\title{
Explicit Analysis of High Impact Collision of Heavy Vehicle on Bridge Pier on Autodyn
}

\author{
Yadukrishna M S ${ }^{1}$, Ann Mary Thomas ${ }^{1}$, \\ Adarsh Krishnan ${ }^{1}$, Aswanth K $\mathrm{P}^{1}$ \\ ${ }^{1}$ Student: Department of Civil Engineering, \\ College Of Engineering and Management Punnapra, \\ Kerala, India,
}

\author{
Vinu Vijayan ${ }^{2}$ \\ ${ }^{2}$ Assistant Professor, \\ Department Of Civil Engineering, \\ College of Engineering And Management Punnapra, \\ Kerala, India, Contact
}

\begin{abstract}
In highways and Expressways vehicles pass through underbridges and other nearby supporting structures at high speeds of over $80 \mathrm{Kmph}$ to $140 \mathrm{Kmph}$. The impact of heavy trucks on a bridge substructure can lead to progressive collapse of the bridge superstructure, and to disastrous accidents. This type of load should therefore be taken into consideration, especially in the design of motorway bridges. In this study a numerical investigation of high velocity impact of heavy trucks on bridge piers is investigated. Here high-speed impact in different angles are investigated and precise design measures are adopted to strengthen the bridge against heavy impacts. A nonlinear material model of concrete with damage and strain-rate effect is used to assess the impact performance of a bridge pier. From this explicit analysis further presents the results that are focused on the influence of different types of bridge pier reinforcement arrangement on their resistance to heavy vehicle impact. The performance of various types of reinforcement is analysed and compared. Practical recommendations are drawn for the design of bridge piers which can be subjected to vehicle impacts in an urban environment. The dynamic behavior of the reinforced concrete (RC) bridge pier is to be compared with the dynamic behavior of the same pier with a CFRP wrapped model
\end{abstract}

\section{Keywords - Impact,bridge piers, autodyn,rht,cfrp wrapping}

\section{INTRODUCTION}

Accidents involving vehicle collisions could severely affect the safety of the users as well as the overall functionality of the infrastructure. While vehicle collisions with bridge piers are rare extreme loading event that can occur during a bridges life cycle, the amount of damage as a result of it can be catastrophic. Out of all the causes for a bridge failure such as flood, scour, deterioration, overloading and seismic loads, vehicle collisions were the second leading cause for failure. A bridge failure would result in detrimental economic impacts; impose danger to the user's safety, with a possibility of loss of life. Direct economic impacts would consist of immediate repair costs or even costs associated with replacing the entire bridge. Indirect costs associated with the bridge repair are significant as well. If the failed bridge is an important component of a transportation network, the disruption of the traffic circulation due to the added detours would be major. Due to the severe consequences of a bridge collapse, the satisfactory design of piers to withstand the expected loadings without failure is of great importance.

Increasing highway congestion and rising speed limits around the world have led to an increase in truck-pier collisions, which have heightened the concern of bridge owners and raised the interest of researchers. Most of the research conducted to date has been computational, where numerical models of trucks are crashed into models of single piers or entire bridges. However, progress in this area has been hindered by the lack of high-quality computational models of trucks. The commonly used F800 truck model is classified as a medium duty vehicle and generally weighs about $90 \mathrm{kN}$ (9177.44 kg). Yet, collision events that involve severe bridge damage are generally caused by heavy-duty trucks, generally tractor-semitrailers weighing $360 \mathrm{kN}$ $(36709.78 \mathrm{~kg})$.

\section{LITERTAURE REVIEW}

With the development of transportation modes and facilities, the number of elevated bridge structures also increased. The high-speed elevated metro rail bridges usually steps across the roadways and therefore the bridge piers are more exposed to vehicle collisions. The term collision can be related to the conventional law of conservation of momentum which involves the collision of two bodies of different masses and different velocities. Many accidental heavy vehicles collisions with bridge piers have noticed in the past. Some of them had led to many catastrophic consequences and may sometimes result in serious risks like failure of the bridge system and even loss of many human lives.

Agrawal et al. [1] investigated the behavior of concrete bridge piers subjected to heavy truck impact. The truck model represented a $360-\mathrm{kN}$ tractor-semitrailer and was validated against a field test. Three main sources of impact demand were identified: bumper, engine, and trailer. Each was shown to deliver a spike in the applied impact force. The simulation results showed that impact from the engine block usually resulted in the highest peak force, which was closely associated with the impact velocity of the vehicle. Two other significant limitations of the AASHTO (2017) [2] guidelines can be identified. First, the impact force is not applied at a constant height as noted in AASHTO (2017) [2], but rather, it is delivered at three separate heights (related to bumper, engine, and trailer) with widely differing intensities. Second, and most important, the design intent of the guidelines is not clear. Miele et al. [3] developed a detailed finite-element model (FEM) of a tractor-semitrailer with a total weight of $360 \mathrm{kN}$. The model was developed for LS-DYNA platform for crashworthiness studies of barriers. The truck model represents a van-type tractor semitrailer with dimensions of $20 \times 3 \times 4 \mathrm{~m}$. The model has approximately 472,000 finite 
elements, including shell, beam, and solid elements for different parts of the truck.

In order to validate the truck modeling scheme, the original tractors semitrailer model developed by Miele et al [3] was modified to match to the extent possible the truck used in the tests conducted by Buth et al [4]. The modifications entailed extensive changes to the material models used, changes to various failure criteria, remeshing of some components, modification of the connection between various parts and adding or removing mass to key components to better match the real truck used in the study by Buth et al [4]. The truck in the full-scale test performed by Buth et al. [4] traveled at $80 \mathrm{~km} / \mathrm{h}(50 \mathrm{mi} / \mathrm{h})$ and collided head-on with a rigid column. The peak reaction force caused by the trailer measured during the test was $2,140 \mathrm{kN}$, whereas the computed peak force was $2,229 \mathrm{kN}$, a reasonably close comparison.

Fujikake et al [5] examined the impact responses of reinforced concrete RC beams through an experimental study and presents an analytical model developed to predict the maximum midspan deflection and maximum impact load, which aids as an important performance index to evaluate the damage levels of RC beams when subjected to impact loadings. It was observed that the local failure was formed shortly after impact by comparing the analytical midspan deflections to those obtained from the experiments conducted. Extensive sensitivity studies by $\mathrm{Xu}$ [6] and Agrawal et al. [1] have shown that the bridge structural system could be simplified into a more tractable model. The simplified model gives results that are reasonably consistent with the full bridge model in terms of failure mode as well as force and displacement time histories. Tawil et al. [7] used FE simulations to investigate the demands imposed by a truck colliding with a bridge pier and data showed that the truck weight alone is not directly correlated with the peak force delivered to the bridge pier. Rather the impact velocity, structural characteristics of the colliding truck, and the geometry and the properties of the pier itself plays a significant role.

Wicklein et al [8] described the derivation and validation of a numerical material model that predicts the highly dynamic behaviour of CFRP (carbon fibre reinforced plastic) under hypervelocity impact. CFRP is widely used in satellites as face sheet material in CFRP-Al/HC sandwich structures ( $\mathrm{HC}^{1} / 4$ honeycomb) that can be exposed to space debris.

Vehicles collisions on bridge piers are becoming a frequent issue due to overcrowding of vehicles in city roads, encroached spaces and lack of recommended margin around bridge piers etc. The safety of bridge structures, traffic systems and human lives etc are dramatically affected by such collisions and can cause damage to the support piers and exposed the whole structure to catastrophic failure. Therefore, scientific research is essential in this field due to severe bridge damages. A similar impact event is modeled to ensure the material models and finite element controls are working properly. The bridge pier model is validated with analytical published results (Fujikake et al. [5]). A set of parametric studies and sensitivity analyses were conducted to observe the effects of pier diameter, vehicle impact velocity itself. Also, in the present study an attempt is made to strengthen the pier model using CFRP.

\section{OBJECTIVES}

The objectives of this research work are:

- To determine effect of high-speed heavy truck collision on bridge piers.

- To study the impact of collision with respect to the angle of collision, different high-speed conditions etc.

- To study the impact performance of bridge piers with different reinforcement ratios.

- $\quad$ Strengthening of pier using CFRP.

\section{VALIDATION OF PIER MODEL.}

An important aspect of using finite element analysis for research is validating that the model accurately represents what is being depicted. Physical characteristics such as geometry, material properties, and boundary conditions have to be modeled to match precisely that of the experimental test setup. The model can be validated by matching displacements and forces with experimental results. Since experimental data for vehicle collisions with bridge piers was very limited, an experiment representing a similar impact phenomenon was used for validation purposes. In the current study, the series of experiments conducted by Fujikake et al. [5] were used to validate finite element controls and material properties for use with vehicle impact simulations. The experiment consisted of a reinforced concrete beam subjected to a drop hammer test. The hammer was dropped at different heights where mid-span deflections and impact forces were recorded and used for validation. The following finite element models were created in units of $\mathrm{N}, \mathrm{mm}$, and seconds.

The material non-linearity incorporated for pier model is RHT (Riedel Hiermaier Thoma) Concrete material model. RHT concrete model is an advanced plasticity model for brittle materials. It is particularly useful for modelling the dynamic loading of concrete. It can be also used for other brittle materials such as rocks and ceramics.

The material properties that had to be input for each different size reinforcement bar include mass density, modulus of elasticity, Poisson's ratio, yield stress, the stressstrain curve, and the strain rate scaling effect on the yield stress curve. All sizes of reinforcing bars had a mass density of $7,850 \mathrm{~kg} / \mathrm{m} 3$, a modulus of elasticity of $200 \mathrm{GPa}$, a tangent modulus of $1.5 \mathrm{GPa}$, and a Poisson's ratio of 0.30 . A reinforced concrete beam with a depth of $250 \mathrm{~mm}$, width of $150 \mathrm{~mm}$, and length of $1,700 \mathrm{~mm}$ were subjected to impact loads (Fujikake et al. [6]). Fig 1: shows the layout of the steel reinforcement cage and dimensions of the test beams. A concrete cover of $40 \mathrm{~mm}$ was provided around the reinforcement cage, except at the ends which had $25 \mathrm{~mm}$ of cover. The concrete beams were reinforced with four longitudinal reinforcing bars, two in compression and two in tension, and 23 transverse reinforcing bars spaced $75 \mathrm{~mm}$ apart.

The reinforced concrete beam specimens were subject to impact loads using a drop hammer impact loading machine. The drop hammer had a hemispherical striking head with a radius of $90 \mathrm{~mm}$ and mass of $400 \mathrm{~kg}$. The hammer was dropped freely onto the top surface of the reinforced concrete 
beam at mid-span. The hammer was freely dropped on to the top surface of the reinforced concrete beam at mid-span. Fig 2: shows the drop hammer test setup.
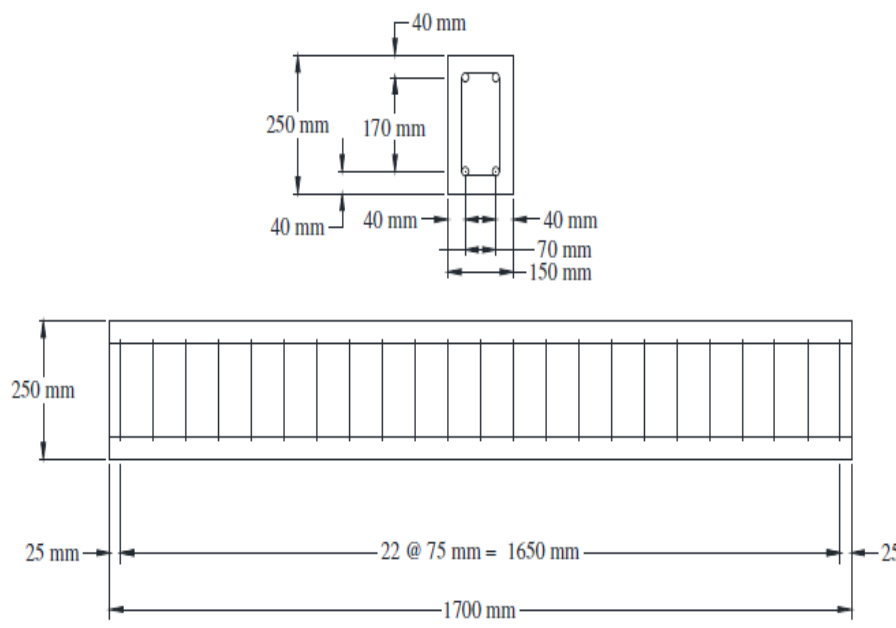

Fig 1: Schematic illustration of the beam cross-section (top) and side view (bottom).

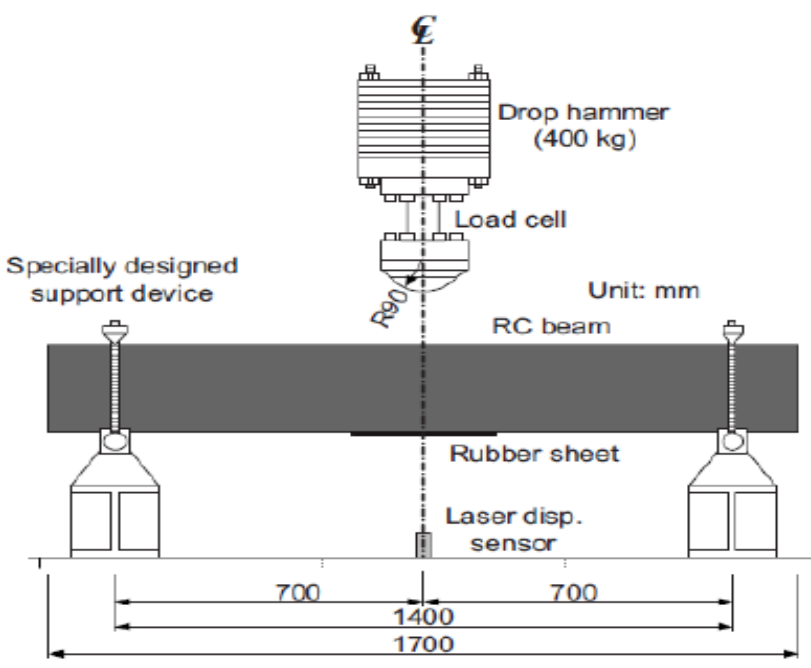

Fig 2: Drop hammer impact test setup (Fujikake et al. [6])

The geometry of the reinforced concrete beam was created using Ansys Design Modeller. The concrete portion of beam was modeled as 3D solid brick elements, whereas rebars were modeled as linear beam elements. There are total 4080 solid elements 460 beam elements and 6781 nodes that make up the finite element model of the reinforced. The bond between beam elements and solid elements were established by defining the body interaction as reinforcement. The drop hammer was also modeled as 3D solid brick elements. The drop hammer consisted of 9616 solid elements and 9438 nodes. In total, the model consists of 15686 elements and 15686 nodes. The finite element model of the beam impact test setup is presented in Fig 3.

The experimental results reported by Fujikake et al. (2009) were compared with the mid-span deflection and impact forces from the analyses. The average difference for mid-span displacement between the simulational and experimental result was $7.001 \%$ for drop height $1.2 \mathrm{~m}$ and $8.716 \%$ for drop height $2.4 \mathrm{~m}$. Overall, the midspan deflections were in good agreement with the experimental results which indicates a realistic performance from the finite element model. The displacement time history is presented in Fig 4.

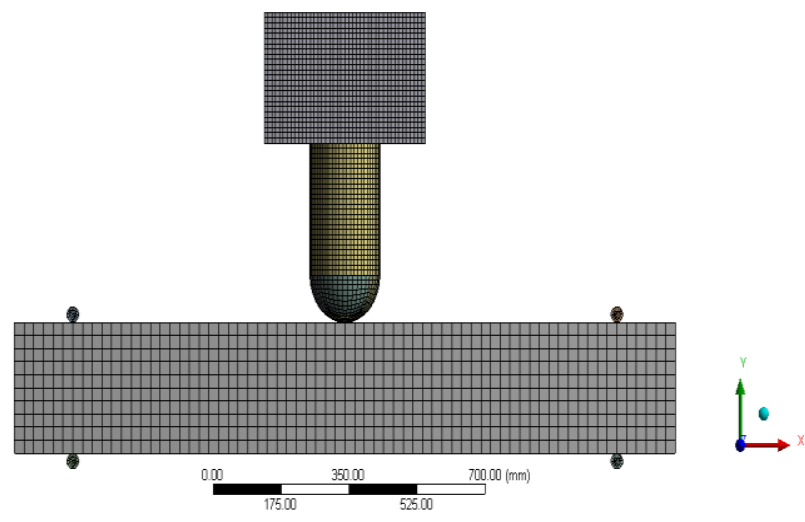

Fig 3: Finite element model of reinforced concrete beam and drop hammer

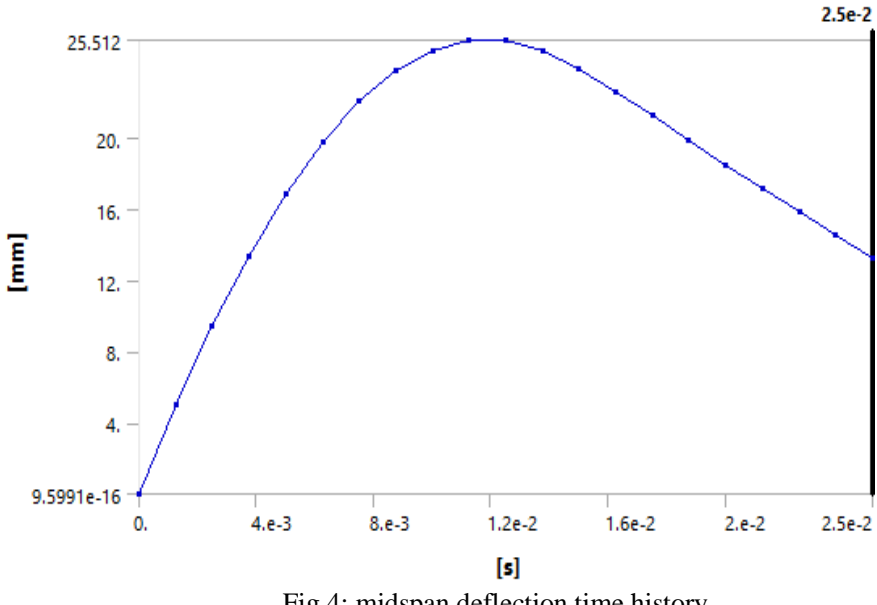

Fig 4: midspan deflection time history

\section{GEOMETRY AND LOADING}

A $360 \mathrm{kN}$ heavy vehicle were used for simulating vehicle collisions with bridge piers. The geometric model of the truck is shown in the Fig 5 and the model represents a van-type tractor-semi trailer with dimensions of $20 \times 3 \times 4 \mathrm{~m}$. The front body of the truck including engine were assembled with trailer portion in Solidworks (2017). The weight of truck model used is $360 \mathrm{kN}$ and is obtained by adjusting density of material used.

The model was $5000 \mathrm{~mm}$ tall, and is adopted from the Agarwal et al [2] which represents typical bent in the United States. Total 3 pier cross sections were used in this work as presented in Fig 5, where S800 indicates a square pier of 800 $\mathrm{mm}$ side and C1100 indicates circular pier of diameter 1100 $\mathrm{mm}$. Geometry of the reinforced concrete pier model was created using Ansys Design Modeller. The concrete portion of beam was modeled as 3D solid brick elements, whereas rebars

were modeled as linear beam elements. The material model for CFRP were modeled in Autodyn and the case has been represented as S1100-CFRP-V80 and S1100-CFRP-V120, where S800-CFRP indicates a square pier of $800 \mathrm{~mm}$ size wrapped with CFRP of thickness $10 \mathrm{~mm}$ and V80 and V120 
represents truck velocity $(80 \mathrm{~km} / \mathrm{h}$ and $1201 \mathrm{~m} / \mathrm{h})$. Material property for CFRP has been obtained from Wicklein et al [7]. The impact setup of model is presented in the fig 6 .

Vehicle impact simulations were conducted at two velocities $80 \mathrm{~km} / \mathrm{hr}$ and $120 \mathrm{~km} / \mathrm{hr}$. The initial translational velocities were applied to the vehicles in the global $\mathrm{x}$ direction using the initial velocity keyword. Gravitational effects were applied to the system using dynamic relaxation to preload the model before conducting the transient analysis.

\section{FE MODELING}

The FE modeling is conducted on ANSYS Autodyn. A total of 109934 nodes and 592715 elements made up the vehicle and pier models. The pier models consisted of total 4080 solid elements 460 beam elements and 6781 nodes that make up the finite element model of the reinforced. The fem model setup is shown in the Fig 7. The bond between beam elements and solid elements were established by defining the body interaction as reinforcement.

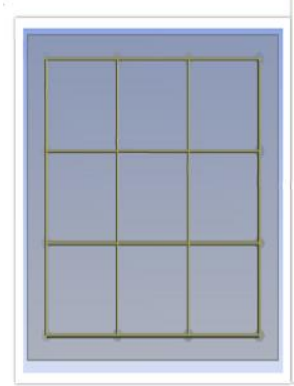

(a)

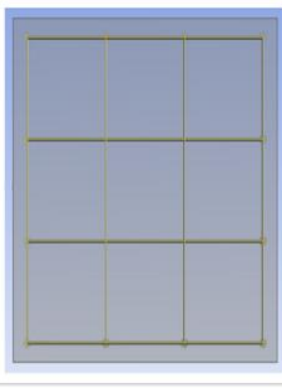

(b)

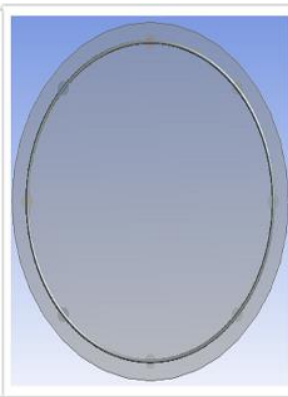

(c)

Fig 5: Cross-section configuration of the six sample bridge piers: (a) S800, (b) $\mathrm{S} 1100$, (c) $\mathrm{C} 11000$

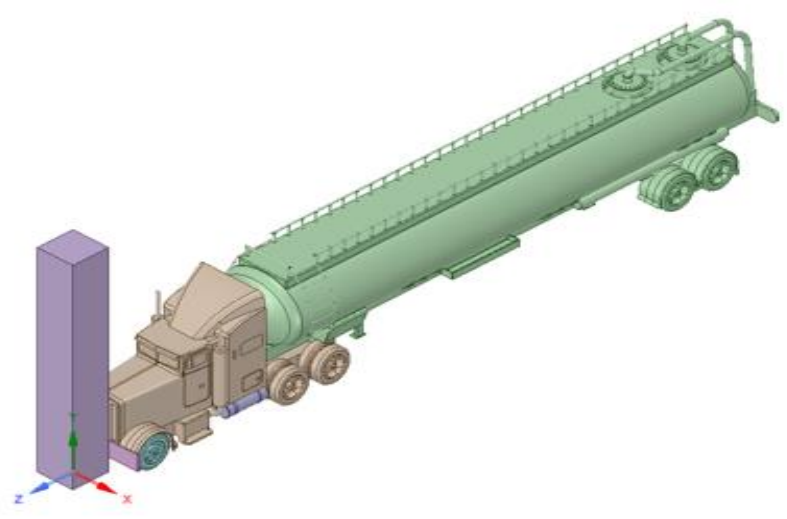

Fig 6: Impact setup for truck collision on bridge pier.
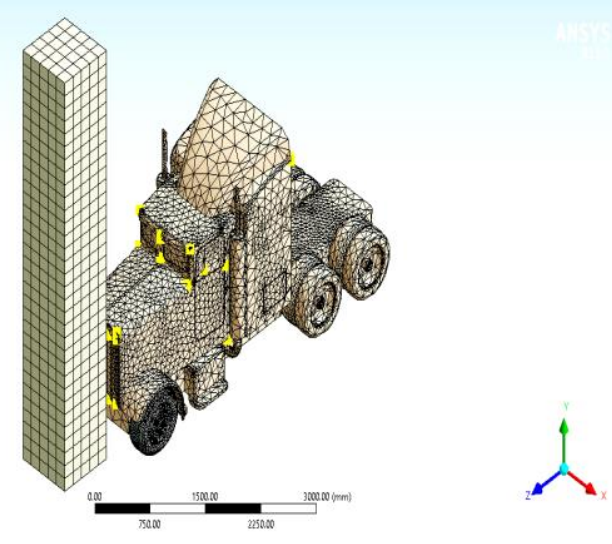

Fig.7. Finite-element model setup.

\section{RESULTS AND DISCUSSIONS}

The deflection occurred in each pier type is collected and compared. The RC pier without any wrapping is compared with the RC pier with CFRP wrapping (Fig. 8, 9). Table 1 shows the comparison of performance of the four models under collisions with different speed conditions. The problem was solved for $300 \mathrm{~ms}$ in order obtain the optimum displacement under collision.

Table 1: comparison of deformation registered for various pier models

\begin{tabular}{|c|c|c|c|c|}
\hline SLNO: & $\begin{array}{c}\text { PIER } \\
\text { MODEL }\end{array}$ & $\begin{array}{c}\text { LONG: } \\
\text { BARS }\end{array}$ & STIRRUPS & $\begin{array}{c}\text { DEFORMATION } \\
(\mathrm{mm})\end{array}$ \\
\hline 1 & $\begin{array}{l}\text { S800- } \\
\text { V120 }\end{array}$ & $\begin{array}{c}\# 12\left({ }^{\$ 3} 2 \mathrm{~mm}\right) \\
4 \times 4\end{array}$ & $\begin{array}{c}10^{\Phi} @ 300 \\
\mathrm{~mm} \mathrm{c} / \mathrm{c}\end{array}$ & 3780 \\
\hline 2 & S800-V80 & $\begin{array}{c}\# 12\left({ }^{\$ 32} \mathrm{~mm}\right) \\
4 \times 4 \\
\end{array}$ & $\begin{array}{c}10^{\phi} @ 300 \\
\mathrm{~mm} \mathrm{c} / \mathrm{c}\end{array}$ & 794.96 \\
\hline 3 & $\begin{array}{l}\text { S1100- } \\
\text { V120 }\end{array}$ & $\begin{array}{c}\# 12(\$ 43 \mathrm{~mm}) \\
4 \times 4\end{array}$ & $\begin{array}{c}43^{\Phi} @ 300 \\
\mathrm{~mm} \mathrm{c} / \mathrm{c}\end{array}$ & 712.3 \\
\hline 4 & $\begin{array}{l}\text { S1100- } \\
\text { V80 }\end{array}$ & $\begin{array}{c}\# 12(\$ 43 \mathrm{~mm}) \\
4 \times 4\end{array}$ & $\begin{array}{c}43^{\phi} @ 300 \\
\mathrm{~mm} \mathrm{c} / \mathrm{c}\end{array}$ & 471.98 \\
\hline 5 & $\begin{array}{l}\text { C1100- } \\
\text { V120 }\end{array}$ & $\# 8(\$ 43 \mathrm{~mm})$ & $\begin{array}{c}43^{\Phi} @ 150 \\
\mathrm{~mm} \mathrm{c} / \mathrm{c}\end{array}$ & 729.93 \\
\hline 6 & $\begin{array}{c}\text { C1100- } \\
\text { V80 }\end{array}$ & $\# 8(\$ 43 \mathrm{~mm})$ & $\begin{array}{c}43^{\Phi} @ 150 \\
\mathrm{~mm} \mathrm{c} / \mathrm{c}\end{array}$ & 432.03 \\
\hline 7 & $\begin{array}{c}\text { S1100- } \\
\text { CFRP- } \\
\text { V80 }\end{array}$ & $\begin{array}{c}\# 12(\$ 43 \mathrm{~mm}) \\
4 \times 4\end{array}$ & $\begin{array}{c}43^{\phi} @ 150 \\
\mathrm{~mm} \mathrm{c} / \mathrm{c}\end{array}$ & 386.59 \\
\hline 8 & $\begin{array}{c}\text { S1100- } \\
\text { CFRP- } \\
\text { V120 }\end{array}$ & $\begin{array}{c}\# 12(\$ 43 \mathrm{~mm}) \\
4 \times 4\end{array}$ & $\begin{array}{c}43^{\phi} @ 150 \\
\mathrm{~mm} \mathrm{c} / \mathrm{c}\end{array}$ & 598.53 \\
\hline
\end{tabular}

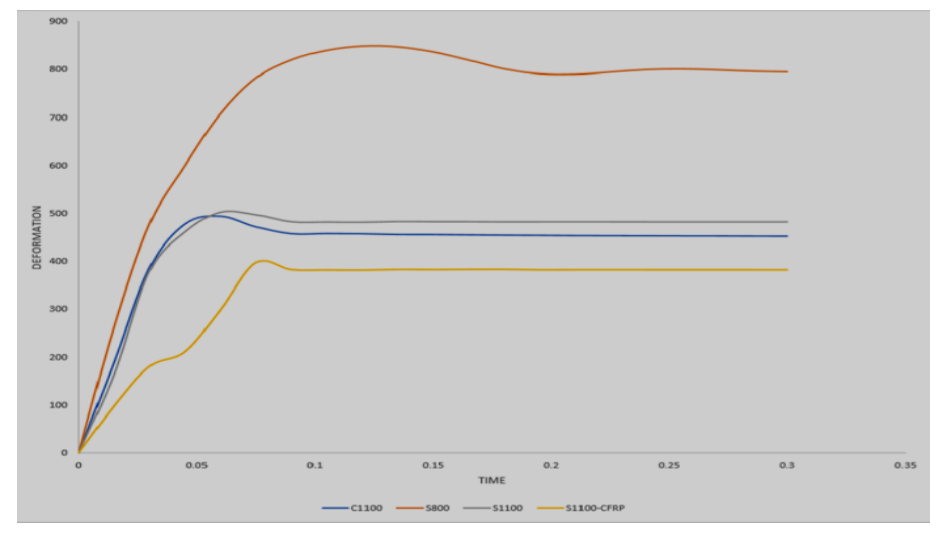

Fig 8: Displacement-time history for various pier models under truck collision with $80 \mathrm{~km} / \mathrm{h}$ speed 


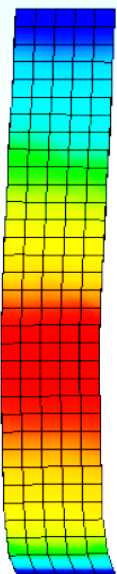

(a)

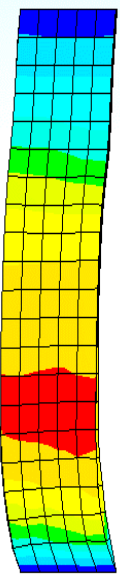

(b)

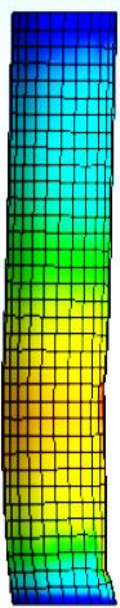

(c)

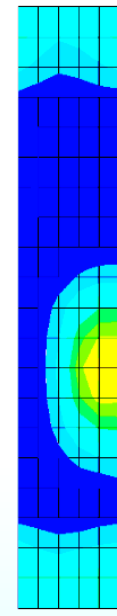

(d)
Fig 9: displacement in pier models when subjected to truck collision with velocity 80km/h: ((a)S800, (b)S1100, (c)C1100, (d)C1100-CFRP)

\section{CONCLUSION}

Using computational simulation, this study investigated the behavior of concrete bridge piers subjected to heavy truck impact. The overall modeling scheme was validated against impact test data in the literature and used to develop detailed insight into the crash process. From the comparative study of various pier models subjected high impact of collision by a $360 \mathrm{kN}$ heavy vehicle, the following conclusions are made:

- S800-V120 case registered large displacement when compared to all other cases, and the pier has been totally collapsed after collision.

- In all cases the maximum displacement is found to be concentrated more on the location where the impactor met.

- The $1200 \mathrm{~mm}$ pier performed well due to its adequate stiffness allowing it to fully absorb and transfer the kinetic energy of the vehicle to the supports without causing significant structural damage. Stiffness of the pier was of great importance in resisting the impact loads.

- For larger velocity square pier is found to be more efficient than circular. But for smaller velocity (V-80) circular pier offered more resistance against impact.

- In all cases, $\mathrm{RC}$ piers are more affected by the collision impact force than CFRP strengthened columns.

- Deformation registered for S1100-CFRP is $16 \%$ to $20 \%$ less than that registered for RC piers.

- Hence CFRP wrapped pier is considered to have better performance than $\mathrm{RC}$ piers and need more studies based on.

\section{REFERENCES}

[1] AnilKumarAgrawal, Sherif El-Tawil, Xiaochen Xu "Heavy Truck Collision with Bridge Piers: Computational SimulationStudy" J. Bridge Eng., 2019, 24(6): $04019052 \quad$.DOI:10.1061/(ASCE)BE.19435592.0001398.

[2] AASHTO. 2017. AASHTO LRFD bridge design specifications. 8th ed. Washington,DC:AASHTO.

[3] Miele, C. R., C. Plaxico, D. Stephens, and S. Simunovic. 2010. U26: "Enhanced finite element analysis crash model of tractor-trailers (phase C)". Knoxville, TN: National Transportation Research Center, Inc., Univ.TransportationCenter.

[4] Buth, C. E. M. S. Brackin, W. F. Williams, and G. T. Fry, 2011. "Collision load s on bridge piers: phase2 ". Report of guidelines for designing bridge piers and abutments for vehicle collisions. Rep. No FHWA/TX-11/94973-2. College Station, TX:Texas Transportation Institute.

[5] Fujikake,K.,B.Li,andS.Soeun.2009.“Impact response of reinforced concrete beam and its analytical evaluation.” J. Struct. Eng. 135 (8): 938-950.https://doi.org/10.1061/(ASCE)ST.1943-541X.0000039.

[6] Xu,X.,R.Cao,S.El-Tawil,A.K.Agrawal2019. "Loading definition and design of bridge piers impacted by medium weight trucks." J. Bridge Eng. 24 (6): 04019042. https://doi.org/10.1061 /(ASCE)BE.19435592.0001397.

[7] El-Tawil, S., E. Severino, and P. Fonseca. 2005. "Vehicle collision with bridge piers." J. Bridge Eng. 10 (3): 345-353. https://doi.org/10.1061 /(ASCE)1084-0702(2005)10:3(345).

[8] M. Wicklein, S. Ryan, D.M. White, R.A. Clegg. 2008, "Hypervelocity impact on CFRP: Testing, material modelling, and numerical simulation" doi:10.1016/j.ijimpeng.2008.07.015

\section{BIOGRAPHIES}
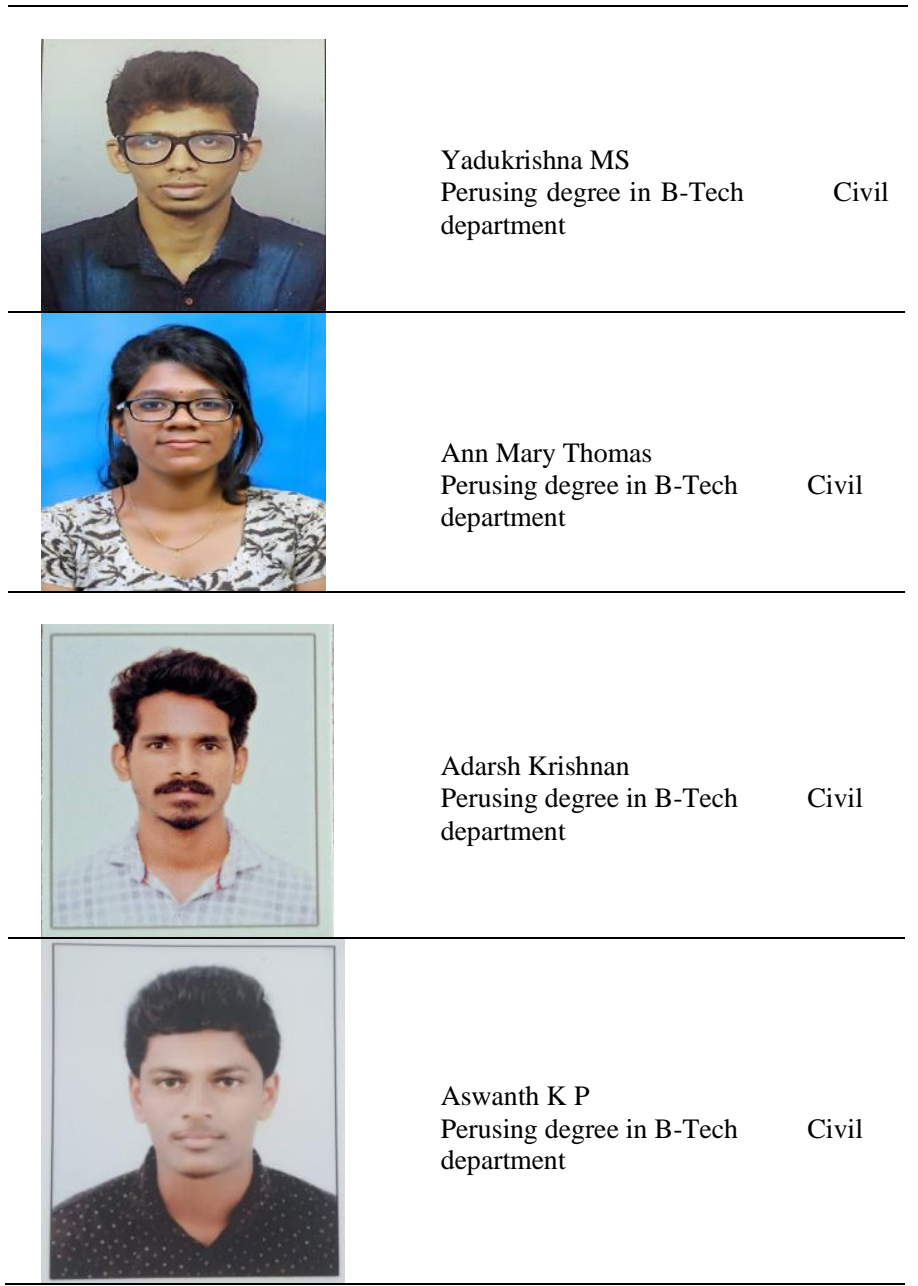